\title{
ECSTASY-INDUCED MALIGNANT HYPERTHERMIA WITH FATAL OUTCOME: A CASE REPORT
}

\author{
RYBarova V, Kumicikova I, Novomesky F, Straka L, KRAJCOVIC J, JANIK M.
}

Department of Forensic Medicine and Medicolegal Expertises, Jessenius Faculty of Medicine in Martin, Comenius University in Bratislava, and Martin University Hospital, Martin, Slovak Republic

\section{A b s tract}

3,4-methylenedioxymetamphetamine (MDMA), also known as "ecstasy", "tulips", or "Molly", is an increasingly used "recreational drug" particularly among teenagers and young adults along with the widespread conviction that MDMA is a "safe drug". The reason for this substance being abused is a desire for closeness to other people, develop a greater tolerance of their views and feelings, and even to touch them physically. According to these effects MDMA is classified also as an "empatogenic" or "entactogenic". Although MDMA is used for the above-mentioned socially acceptable purposes, in many individuals the drug usage is followed with side-effects varying from mild to severe, potentially even life-threatening. One of the most significant complication of MDMA intoxication is hyperthermia in the consumer. Authors presented a case of MDMA toxicity with severe hyperthermia $\left(42{ }^{\circ} \mathrm{C}\right)$ with a fatal outcome to the ecstasy-influenced subject. The aim of this article is to describe the effects of ecstasy, the "recreational drug" widely used in local pubs, dance clubs, and during open air festivals, even in the Slovak Republic.

Keywords: 3,4-methylenedioxymethamphetamine, MDMA, ecstasy, hyperthermia, drug toxicity

\section{INTRODUCTION}

3,4-methylenedioxymethamphetamine (MDMA), commonly known as "ecstasy", is a ringsubstituted amphetamine derivative with stimulant and hallucinogenic properties, used as a popular "recreational drug" $(1,2)$. Effects, for which such a psychoactive substance is usually used by young people, are experiences of a relaxed, euphoric state characterized by increased empathy, openness, communication, and tranquility (2). MDMA as a "dance drug" is linked with attendance at "raves", all-night dance events with fast-paced electronic music (2). Mood-enhancing properties of this psychoactive substance could be summarized in the 3 Es: energy, empathy, and euphoria (3). Although MDMA is often considered as being a "safe" drug, use of this stimulant is associated with significant morbidity and mortality $(3,4)$. Typical "recreational" doses of MDMA are 1 to $2 \mathrm{mg} / \mathrm{kg}$. The onset of effects occurs between 30 and 60 minutes after ingestion (2). The side-effects of ecstasy vary from mild to severe, potentially life-threatening. Mild clinical symptoms and signs seen with MDMA are tachycardia, mydriasis, feeling of dry mouth, profound sweating, and bruxism (jaw clenching) (3). Severe adverse reaction as hyperthermia, seizures, hypertensive crises, cardiac dysrhythmias, metabolic disturbances, disseminated intravascular coagulation (DIC), rhabdomyolysis, acute kidney or liver failure, cerebrovascular episodes, psychiatric disturbances, or accidents / injuries can lead to fatalities related to MDMA intoxication $(3,4,5)$. The authors report a case of a young man who consumed MDMA and within a short time developed hyperthermia, delirious behavior, and seizures leading to death. The aim of this article is to point out the side-effects of such an "innocent" drug, popular even in Slovakia.

Corresponding author: Lubomír Straka, MD, PhD, Assoc Prof.; e-mail: lubomir.straka@uniba.sk

(C) 2021 Straka L. et al.

This work is licensed under the Creative Commons Attribution-NonCommercial-NoDerivs 4.0 License (https://creativecommons.org/licenses/by-nc-nd/4.0/) 


\section{CASE REPORT}

A 23-year-old previously healthy male was admitted to the emergency department after a sudden onset of generalized seizures at a local rave party. The consuming of any illicit drugs by the subject was denied by his friends. There was seriously pronounced verbal and brachial aggression, agitation, and seizures escalated into the patient's consciousness disorders (Glasgow coma scale of 8 ) prior to the hospital admission. Initial vital signs revealed an oral temperature of $42^{\circ} \mathrm{C}$, a heart rate of 130 beats per minute with a blood pressure drop to $100 / 70 \mathrm{~mm} \mathrm{Hg}$. Initial blood glucose was $4.2 \mathrm{mmol} / 1$. Physical examination showed hot sweaty skin with diffuse intermittent myoclonic activity and mydriasis with massive conjunctival hyperaemia. After arrival to the hospital the patient's condition dramatically worsened, accompanied by profuse vomiting, sudden quantitative decrease of consciousness (Glasgow coma scale of 3), and cessation of vital functions. The skin of the victim was mottled with marked cyanosis on the upper part of the body. The patient underwent forceful resuscitation involving endotracheal intubation, after 45 minutes of resuscitation efforts the patient was declared dead. Urine toxicology screening for drugs of abuse was not performed by paramedics or ambulance before his death. The cause of death in the presented case was hyperthermia by lethal MDMA intoxication.

\section{Autopsy}

The external examination revealed upper body part cyanosis with demarked multiple petechial haemorrhages localised mainly on the victim's torso. The internal examination revealed gross congestion and oedema of all internal organs (brain 1,620 g, right lung 1,020 g, left lung $730 \mathrm{~g})$. All other macroscopical findings were in accordance with the patient's age as well as histopathological findings which were non-specific (interstitial myocardial oedema, massive pulmonary oedema, brain oedema).

\section{Toxicology}

Post-mortem forensic toxicology revealed elevated serum concentrations of 3,4-methylenedioxymethamphetamine (MDMA) $(437 \mathrm{ng} / \mathrm{ml})$ and 3,4-methylenedioxyamphetamine (MDA) (398 ng/ml). Urine toxicology screen for psychoactive substances was positive for amphetamine (AMP), methamphetamine (MET), and 3,4-methylenedioxymetamphetamine (MDMA).

\section{DISCUSSION}

3,4-methylenedioxymethamphetamine (MDMA) is a ring-substituted derivative of methamphetamine (Fig. 1). It was first synthetized in 1914 and later, in the 1970s, was evaluated as an adjuvant treatment to the psychotherapy. MDMA was becoming widely available recreationally since then. Therefore, in 1985 the drug was placed by U.S. Drug Enforcement Administration on Schedule I of controlled substances (6).

MDMA is usually taken orally in the form of tablets or pills. Less frequently, it can also be administered intravenously or by "snorting" the powder. Ecstasy is sold commonly as tablets of various colours weighing 50-150 mg, stamped with a wide variety of symbols. The chemical composition of tablets varies based on MDMA content. Many ecstasy tablets contain psychoactive substances other than MDMA such as dextromethorphan, amphetamine, methamphetamine, ketamine, or caffeine. Thus, a drug sold as "ecstasy" may be MDMA but also MDEA (methylenedioxyethylamphetamine), MDA (methylenedioxyamphetamine), MPA (para-methoxyamphetamine), MBDB (3,4-methylenedioxy-phenyl-N-methylbutanamine), ephedrine, or mixtures of these as showed by analysis of several different laboratories. Tablets containing $60-80 \mathrm{mg}$ of MDMA are considered as a high-quality substance $(5,6)$.

Desired effects after ingestion of typical "recreational" dose of MDMA (50-150 mg) appear within 30 to 60 minutes and last for 4 to 6 hours. A peak plasma concentration of MDMA 


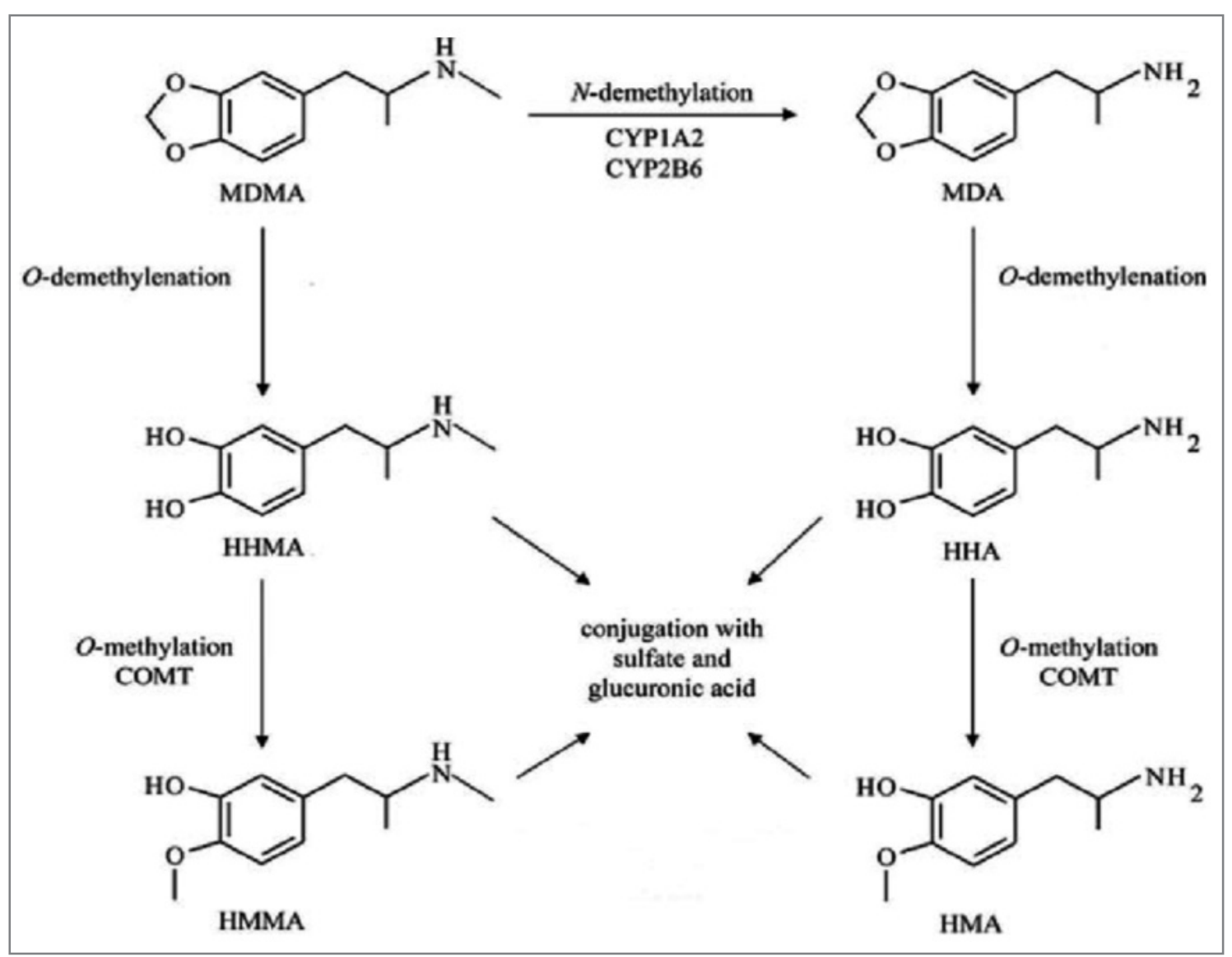

Fig. 1 The metabolism of MDMA (6).

is reached approximately 2 hours after the oral administration $(2,6)$. The plasma half-life of MDMA is about 8 to 9 hours. MDMA and its first metabolite, MDA (methylenedioxyamphetamine), are pharmacologically active but the hydroxylated metabolites probably do not significantly contribute to the overall effects of the drug (5). MDMA causes the release of the monoamine neurotransmitters (serotonine, noradrenaline, dopamine) in the central nervous system. Anyway, MDMA acts also by binding to and inhibit their reuptake inhibitors at the synapse, principally serotonin. The result is an acute increase in the intra-synaptic concentration of these neurotransmitters, followed by a rather lengthy period of depletion. The mentioned compounds are involved in the control of mood, sleep, autonomous nervous system, as well as in the central control of thermoregulation $(7,8)$. MDMA effects lead to the activation of mechanisms that conserve and generate the heat and serotonin syndrome is probably the most extreme of these effects (3). Increase of cortisol, prolactin, and adrenocorticotropic hormone blood levels has been shown after MDMA administration and it has been suggested that prolactin may be responsible for the emotional closeness feeling, simulating post-orgasmic state (9).

Physical effects as endurance, sense of energy, sexual arousal, and wakefulness are accompanied by psychological effects described as a sense of euphoria, well-being, sharpened sensory perception, greater sociability, and close feelings to other people (entactogenicity of MDMA). In summary, the desired effects for which the drug is used are similar to other amphetamines (e.g. methamphetamine) and hallucinogens (LSD) $(5,6)$. 
Side-effects of MDMA vary from mild symptoms (tachycardia, trismus, bruxism) to those that are rare but potentially life-threatening. These are not clearly dose-dependent but could be interpreted as idiosyncratic (2). Hence, even a small increase in dosage may carry a risk of serious toxicity. The most important MDMA-induced life-threatening reaction is hyperthermia that can lead to rhabdomyolysis, DIC, and acute renal failure. The increased muscle activity (seizures, jerky spasms of the whole body) for dozens of minutes, together with a direct action of the drug on the thermoregulatory system, result in an extensive increase of body temperature, whereas high ambient temperature, exertion (e.g. prolonged high-energy dancing before an attack of hyperthermia), and dehydration may act as additional permissive factors. Thus, most of the severe morbidity and mortality associated with MDMA use can be attributed to hyperthermia effects (2). Although the side-effect of MDMA consumption could be hypertension, on the other side hyperthermia could lead to vasodilatation result in hypotension except from the fact high body temperature cause permanent damage of brain regulation centers. One hypothesis of the user's susceptibility for hyperthermia suggests possible defective metabolism of the drug in organism $(4,5,10)$. The process of biotransformation of MDMA takes part mainly in the liver, largely by the hepatic cytochrome-P450 isoform CYP2D6. Some of different enzymes involved in the degradation of MDMA appear to be saturated at relatively low drug concentrations. Hence, when these enzymes are saturated and MDMA dose is increased, disproportional enhancement in blood and brain concentrations of the drug occur. As 5-9\% of Caucasians displays genetic polymorphisms of CYP2D6, this part of population is being suspected to be at a higher risk of acute MDMA toxicity. Unfortunately, the genetic testing of patients intoxicated by ecstasy has not been carried out $(2,3,11)$. Another possible cause of toxicity of MDMA are ecstasy pill contaminants, so negative drug screen for any additional substances must be interpreted cautiously. There may be present co-ingestants that are not typically detectable (e.g. lysergic acid diethylamide, LSD) or may not be tested for (e.g. cocaine, ketamine) (11).

In the presented case the toxicology examination revealed the serum concentration of MDMA (437 ng/ml) significantly higher than the usual "recreational" dose (100-150 ng/ml). Lethal serum concentration ranges between $500 \mathrm{ng} / \mathrm{ml}-10,000 \mathrm{ng} / \mathrm{ml}$, but many authors point out the degree of the seriousness depends likewise on factors other than the drug concentration itself $(2,5,6)$. The higher concentration of the first metabolite MDA (398 $\mathrm{ng} / \mathrm{ml})$ declared a prolonged metabolic degradation of the drug in the body. The delayed desirable drug effects (about 1-2 hours) may lead to a repeated use of MDMA, which means a consequently increased dosage before the onset of the desired effects, which may appear already in the level of intoxication. According to the testimony of the friends of the deceased there was a suspicion of adding a foreign substance into his beverage by an unknown person, which should be legally considered as a criminal act. The physical properties of ecstasy allow only a partial dissolution of the powder form of MDMA in water together with a significant change in the taste of the beverage. Thus, an involuntary consumption of ecstasy dissolved in any kind of beverage seems very unlikely.

The presented case of fatal outcome of ecstasy overdose in a young man presented by the authors points to a rare but severe MDMA-induced toxicity, in contrary with the mistaken belief in the safe use of MDMA. The dangerous trend of ecstasy (MDMA) consumption as a "recreational drug" is widely accepted among young adults and teenagers, even in the Slovak Republic. According the Annual Report of National Criminal Agency (NAKA) of the Ministry of Inferior of the Slovak Republic, there were 2,370 pills of ecstasy seized in Slovakia by the police authorities in 2017 (12). However, high this number seems to be, it represents only a "peak of an iceberg" of the Slovak drug scene. Emergency doctors and physicians should be alert to the existence of ecstasy drug in the Slovak Republic, realize the growing tendency of using that drug within the youngsters at specific occasions, and recognize its extremely dangerous side-effects threatening health or life of otherwise healthy population of young people. 


\section{REFERENCES}

1. Meyer JS. 3,4-methylenedioxymethamphetamine (MDMA): current perspectives. Subst Abuse Rehabil 2013; 4: 83-89.

2. Armenian P et al. Multiple MDMA (Ecstasy) overdoses at a rave event: a case series. J Intensive Care Med 2012; 28 (4): 252-258.

3. Hall AP, Henry JA. Acute toxic effects of "Ecstasy" (MDMA) and related compounds: overview of pathophysiology and clinical management. Br J Anaesth 2006; 96 (6): 678-685.

4. Connolly E, O'Callaghan G. MDMA toxicity presenting with severe hyperpyrexia: a case report. Crit Care Resusc 1999; 1: 368-370.

5. Kalant H. The pharmacology and toxicology of "ecstasy" (MDMA) and related drugs. CMAJ 2001; 165 (7): 917-928.

6. Baselt, RC. Disposition of toxic drugs and chemicals in man. Tenth Edition. California: Biomedical Publications; 2014.

7. Fiege $M$ etal. Induction of malignant hyperthermia in susceptible swine by 3,4- Methylenedioxymethamphetamine (“Ecstasy”). Anesthesiology 2003; 99 (5):1132-1136.

8. Green AR et al. The pharmacology and clinical pharmacology of 3,4-methyledioxymethamphetamine (MDMA, "Ecstasy"). Pharmacol Rev 2003; 55: 463-508.

9. Passie T et al. Ecstasy (MDMA) mimics the post-orgasmic state:impairment of sexual drive and function during acute MDMA-effects may be due to increased prolactin secretion. Med Hypotheses 2005; 64: 899-903.

10. Lang et al. Fatal Ecstasy-induced malignant hyperthermia with rhabdomyolysis. A case report. Rom J Leg Med 2016; 24: 212-215.

11. Manish et al. Methylenedioxymethamphetamine (ecstasy)-related hyperthermia. J Emerg Med 2005; 29 (4): 451-454.

12. Národná kriminálna agentúra (NAKA), Národná protidrogová jednotka, Prezídium Policajného zboru SR, Ministerstvo vnútra SR. Správa o stave a vývoji drogovej scény na území Slovenskej republiky v roku 2017. Bratislava; 2018.

Received: November, 9, 2020

Accepted: December, 17, 2020 